\title{
Anatomy training for surgeons: Which way for the future?
}

\author{
J.A. Ogeng'o, BSc, MBChB, PhD, Department of Human Anatomy, University of Nairobi. P.O. Box 30197- \\ 00100 Nairobi, Kenya
}

\section{Summary}

Sound knowledge of human anatomy is critical for safe medical practice. Worldwide, reduction in time allocated for its teaching has invoked debate on the extent, mode and timing of instruction, and opinion is divided on the value of dissection vis-à-vis other methods of delivery. In Africa, including Kenya, dissection integrated with microscopic, developmental and neuro-anatomy has remained core practice, even in the few schools which adopted problem based learning. This relatively conservative stance is beginning to be questioned by faculty and students. The objective of this review is to evaluate the role and method of teaching anatomy in medical training in general and surgical in particular. Several papers on teaching of anatomy in medical schools from different parts of the world have been analysed.

The consensus is that teaching of anatomy to undergraduate medical students should be rationalized, horizontally and vertically integrated with other medical subjects and taught using a variety of techniques. Dissection should still be central to the teaching of anatomy and especially for those pursuing surgical careers. Combined efforts between departments of anatomy, surgery, and imaging should therefore be channeled through intensified training of surgeons in human anatomy, so that they can form pillars of teaching anatomy in the continuum of medical training. One such model is intercalating a comprehensive MSc Anatomy course within the MMed, or MD surgery programme.

\section{Introduction}

Proper training in human anatomy is essential for safe medical practice. Deficient anatomy knowledge has been implicated in avoidable iatrogenic injuries. In UK, for example, "damage to underlying structures" is the commonest reason for settlement of claims relating to general and vascular surgery (1). Yet, in many medical schools worldwide, the time allocated to teaching of human anatomy has been reduced. This, combined with shortage of cadavers and instructors has occasioned reduction in or withdrawal of dissection as an instruction mode and utilization of other techniques of instruction. This move may partially explain the worrying decline in quality and quantity of the subject matter being taught to medical students and surgical trainees (2-4). At the moment, opinion is divided between dissection and other techniques of instruction and the extent to which each of these methods is employed varies from one school to another with some abandoning dissection altogether while others rely almost entirely on it (5).

In the majority of African medical schools, dissection is still a constant feature of the human anatomy course (6). However, with diminishing resource allocation to human anatomy departments, there is imminent danger that dissection will be relegated. The effects of this may be more disastrous for developing countries where the surgeon must perform safe surgery yet stateof-art interactive multimedia packages, imaging and laparoscopy are not universally accessible. 
In many countries, topographic anatomy is integrated with microscopic, developmental and neuro anatomy $(7,8)$. With mounting resource constraints, this practice may also fade. This review evaluates the mode of, and human resource for instruction in anatomy in medical training in general and surgical in particular.

\section{Merits of dissection}

Cadaver dissection has been a regular feature in anatomy teaching since Renaissance, evolving into part of the culture in medical education worldwide (9). It has been labelled the "royal road" and the cadaver as the "first patient and teacher of medical education" (10). It is expensive because it requires enormous space, cadavers, instructors and time. Its benefits, however, include:

\section{(a) Development of clinical "habits-of-mind":}

Problem solving in the dissection laboratory develops the clinical "habits-of-mind" and entrenches the rhythm of observation to discover facts, interpretation of findings to develop a differential diagnosis, development and execution of management plan (11). The practice in the dissection laboratory is the same, observation to distinguish recognizable structures from unknown, interpretation of what you see to develop a differential identification and further dissection/exploration to distinguish between the possibilities.

\section{(b) Provision of the navigation maps:}

The location, extents and relations learned through dissection provide essential tools for scientifically navigating the body. One of the best principles in surgery is to adopt the shortest, safest and fastest route to the problem, to remove the diseased part and restore normalcy. For example, in the pterional approach to the brain, one utililises the knowledge that the pterion lies about $3 \mathrm{~cm}$ above the midpoint of zygomatic arch, and overlies the middle meningeal artery, superficial middle cerebral vein, Broca's area and pre-central gyrus. Such knowledge as gained in dissection cannot be overemphasised.

\section{(c) Development of spartial reasoning skills:}

Dissection enables learners to develop a dynamic 3-dimensional (3D) image of the anatomy, and the spartial skills that enable a competent clinician to explain imaging studies to patients and demystify surgical procedures that they may ask their patients to undergo (5).

\section{(d) Provision of the "buman face":}

The practice of dissection furthers the development of professionalism by enhancement of attitudes of ethics, empathy and humanism. It engenders the opportunity to reflect on feelings of mortality, humility and spirituality $(5,12)$.

\section{(e) Reinforcement of other learning modalities:}

Dissection also has the advantage of encouraging small group learning, developing fine motor control, fostering teamwork, and providing an opportunity for learners to integrate knowledge from textbooks and didactic lectures with practice $(9,10)$.

\section{Other methods of teaching Anatomy}

\section{Use of prosected specimens:}

This maximises the resource of cadavers and teachers saving time for teaching, learning, and revision. Plastinated prosected material is more robust and can be handled safely and stored at room temperature, but the rigidity of the tissues limits its use to visualisation.

\section{Live models:}

Living human models enable the learner to see structures move and function, particularly in the musculoskeletal system, and to become familiar with important surface landmarks. Its use also provides students with the opportunity to observe, examine, and interact with a living person. It however does not permit the student to explore beyond the surface and appreciate the body in $3 \mathrm{D}$ nor study the internal organs. 


\section{Use of radiological images:}

Imaging techniques such as computed tomography, magnetic resonance imaging, positron emission tomography, and ultrasonography provide fresh opportunities to present anatomy to learners. The learner nonetheless is not able to see the body or region as a whole from one set, and cannot follow origins, branches and distribution of nerves and vessels for example.

\section{Laparoscopy:}

Telescopic views of internal living anatomy obtained during diagnostic and therapeutic procedures, provide a realistic, effective teaching and learning opportunity (13).

\section{Computer Assisted Learning (CAL):}

This cannot "fully replace" the intellectual, education and emotional experience afforded to medical students by cadaver dissection and even prosection (14), but online interactive programmes are useful tools in enhancing learning in the dissection laboratory (15).

\section{Problem Based Learning (PBL):}

This is an effective way of integrating practical knowledge but runs the risk of undermining the basic science principles needed for logical reasoning, and its efficacy is equivocal $(16,17)$.

\section{Team-based learning (TBL):}

This is learner centred but instructor led. It most benefits academically at-risk students who are forced to study more consistently, are provided regular feedback on their preparedness and given the opportunity to develop higher reasoning skills (18). The components of its strategy (19) suggest that it is relatively theoretical and lacks the practical component critical in clinical thinking.

\section{Rating of modes of instruction}

A recent survey among anatomists reveals the following order of preference for teaching methods: cadaver dissection by students, prosection, living and radiological anatomy, computer aided learning (CAL), and didactic lectures alone and use of models (20). Majority of the clinicians who suggested improvements in the practical part of the course have also recommended the traditional dissection - based model of anatomy teaching calling it a "paramount of medical education" that influences the future attitude of the practitioner towards his or her patients $(21,22)$. Even those who are lukewarm about dissection, nonetheless seem to agree on one point: It should be retained in entirety for those pursuing surgical training $(4,23)$.

Among students, the rating is in the following order: dissection, textbooks, computer aided learning, interactive multimedia programmes, self directed learning and lectures alone (24). Students feel that dissection deepens their understanding of anatomical structures, provides them with a 3-D perspective of structures and helps them recall what they learn. Recent research reveals that, innovations used in teaching anatomy such as interactive multimedia resources have not replaced students' perceptions about the importance of dissection (24).

\section{The value of Integrated teaching of anatomy}

Optimum clinical practice requires a sound knowledge of anatomy, physiology and biochemistry. In the case of anatomy, emphasis is put on integration of topographic, microscopic, developmental and neuro anatomy. This should be in a coordinated fashion, with clinical application where appropriate, constantly drawing the students' attention to professional relevance of the course (8). Indeed, many students believe that the histology course helps them develop critical thinking and enhance problem solving abilities (25).

For surgeons called upon to treat patients with congenital abnormalities, a thorough understanding of embryology is essential. For example, to prevent recurrence when excising a thyroglossal 
duct cyst, a surgeon must realize the need to remove the central portion of the hyoid bone which is the embryonic course of the duct (26). Further, knowledge of the developing human is of practical value in understanding the normal relationships of body structures and causes of congenital anomalies. In other words, embryology "illuminates" anatomy and explains how normal relations develop (27).

\section{When, how and by whom should anatomy be taught today?}

In most schools, anatomy is a pre-clinical subject taught in the first and often second year. There is widespread support among clinicians for more vertical integration of anatomy teaching with para-clinical and clinical courses throughout the undergraduate curriculum (3). The supremacy of one methodology is old fashioned. Dissection should remain core practice as it is in many renown schools $(5,28)$. Its combination with the other methods must, however, be embraced to encourage interest and retention of anatomical knowledge and its clinical relevance (24). To achieve this, it is useful that clinical teachers participate in the so called pre-clinical years, and "pre-clinical" teachers continue teaching the students in the clinical years during clinical teaching rounds, seminars and conferences. There is need to integrate not only the student teaching, but also preclinical and clinical teachers. In this regard, surgeons should be encouraged to take greater responsibility for the sequential teaching. Closer links or integration between departments of surgery and anatomy will help to achieve this and also benefit postgraduate learning $(29,30)$. It is the deep training of the surgical postgraduates by dissection enriched with newer learning methods that will equip them with the requisite skills, knowledge and attitudes appropriate for this role.

\section{Conclusion}

Solid training in human anatomy is core to surgical training to ensure safety in practice. Comprehensive cadaver dissection constitutes the most effective mode of instruction, especially for the surgical trainee. Its combination with other innovative contemporary techniques of instruction should be embraced. Integrating human anatomy horizontally and vertically with other medical subjects is a useful way of improving its retention and application. Surgeons will form pillars of such integrated teaching. Accordingly, their training in human anatomy should be intensified. One practical way of enhancing the current amount of anatomy inbuilt in the MMed surgery programme is to introduce and promote an intensive intercalated programme, in which interested top performers can branch off for a year and pursue an MSc in human anatomy before returning to and completing clinical graduate training leading to MMed or MD in surgery.

\section{References}

1. Goodwin H. Litigation and surgical practice in the UK. Br J Surg. 2000; 87: 977-9.

2. Anon. The rise and fall of anatomy. BMJ Career Focus. 2005; 330: 255256.

3. Waterson S.W. and Stewart I.J. Survey of clinicians attitudes to the anatomical teaching and knowledge of medical students. Clin. Anat. 2005; 18: 380-384.

4. Standring $S$. New focus on anatomy for surgical trainees. ANZ J. Surg. 2009; 79(3): 114-117.

5. Rizzolo L.J. and Stewart W.B. Should we continue teaching anatomy by dissection when .....? Anat. Rec. (part B: New Anat). 2006; 289B: 215 - 218.

6. Kramer B., Pather N. and Ihunwo A.O. Anatomy: Spotlight on Africa. Anat. Sci. Edu. 2008; 1: 111-118.

7. Kagan I.I. Traditions and pecularities of clinical anatomy education in Russia. Clin. Anat. 2002; 15(2): 152-156.

8. Wong W.C. and Tay S.S.W. The Teaching of Anatomy: The first Hundred years (1905 - 2005). Ann Acad. Med. Singapore. 2005; 34: 72c-78c. 
9. McLacham J.C. and Patten D. Anatomy teaching: ghosts of the past, present and future. Med. Educ. 2006; 40: 243-253.

10. Prakash, Prabhu L.V., Rai E., et al., Cadavers as teachers in medical education: Knowledge is the ultimate gift of body donors. Singapore Med. J. 2007; 48: 186-190.

11. Pangaro L.N. A shared professional framework for anatomy and clinical clerkships. Clin. Anat. 2006; 19: 419-428.

12. Gunderman R.B. and Wilson P.K. Exploring the human interior: the roles of cadaver dissection and radiological imaging in teaching anatomy. Acad. Med. 2005; 80: 745-749.

13. Fitzpatrick C.M., Kolesari G.L. and Brasel K.J. Teaching anatomy with surgeons tools: Use of the laparoscope in clinical anatomy. Clin. Anat. 2001; 5: 349-353.

14. Paalman M.H. Why teach anatomy. Anatomists respond. Anat. Rec. 2000; 261: 1-2.

15. Granger N.A., Calleson D.C., Henson O.W., et al. Use of web-based materials to enhance anatomy instruction in the health sciences. Anat. Rec. (B. New Anat). 2006; 289: 121-127.

16. Prince K.J., Vander Wiel M.W., Scherpbier A.J. et al. A qualitative analysis of the transition from theory to practice in undergraduate training in PBL medical school. Adv. Health Sci. Educ. 2000; 5: 105-116.

17. Verhoeven B.H., Verwithnen G.M. and Scherpbier A.J. An analysis of progress test results of PBL and non PBL students. Med. Teacher. 1998; 20: 310-316.

18. Niedel G.L., Parmelee D.X., Stofli A. et al. Team-based learning in a medical gross anatomy and embryology course. Clin. Anat. 2004; 18: 56-63.

19. Parmelee D.X., Destphen D. and Borges N.J. Medical students attitudes about Team-Based Learning in a preclinical curriculum. Med. Educ. online. 2009; 14: 1-6.
20. Patel K.M. and Moxham B.J. Attitudes of professional anatomists to curricular change. Clin. Anat. 2006; 19: 132-141.

21. Ellis H. Teaching in the dissection room. Clin. Anat. 2001; 14: 149-151.

22. Older J. Anatomy: A must for teaching the next generation. J. R. Coll. Surg. Edinb. 2004; 2: 79-90.

23. Turney B.W. Anatomy in a modern medical curriculum. Ann. R. Coll. Surg. Engl. 2007; 89(2): 104-107.

24. Azer S.A. and Eizenberg N. Do we need dissection in an integrated problem-based learning medical course? Perceptions of first and second-year students. Surg. Rad. Anat. 2007; 29(2): 173-180.

25. Nekooelan A., Jahaadi H., PanjehShaahim M., et al. $15^{\text {th }}$ international congress of geographic medicine and $5^{\text {th }}$ national congress of medical education view of students, entry 1995 about histology teaching at Shiraz Medical School. Iran J. Med. Edu. 2002; 2: 6.

26. Gray S.W. and Skandalakis J.E. Embryology for surgeons. AMA Arch. Surg. 1973; 106(2): 246.

27. Moore K.L. and Persaud T.V.N. Significance of embryology. In the developing human: clinicallyoriented embryology $5^{\text {th }}$ Ed. W.B. Saunders Co. 1993; pp 7.

28. Ganske I., Su T., Loukas M. and Shaffer K. Teaching methods in anatomy courses in North American Medical schools. The role of radiology. Acad. Radiol. 2006; 13(8): 1038-1046.

29. Rob M. and Lachlan B. Undergraduate perspectives on the teaching and learning of anatomy. ANZ J. Surg. 2009; 79(3): 118-121.

30. Collins J.P. Is anatomy teaching in crisis? Student BMJ. 2008; 16: 402-408. 